\title{
No detectable cytomegalovirus and Epstein-Barr virus genomes in the pancreas of recent-onset IDDM patients
}

\author{
N. Itoh ${ }^{1}$, T. Hanafusa ${ }^{1}$, K. Yamagata ${ }^{1}$, H. Nakajima ${ }^{1}$, K. Tomita ${ }^{1}$, S. Tamura ${ }^{1}$, M. Inada ${ }^{1}$, S. Kawata ${ }^{1}$, N. Kono ${ }^{2}$, \\ M. Kuwajima ${ }^{1}$, Y. Matsuzawa ${ }^{1}$ \\ ${ }^{1}$ Second Department of Internal Medicine, Osaka University Medical School, Suita, Osaka, Japan \\ ${ }^{2}$ School of Allied Health Sciences, Faculty of Medicine, Osaka University, Toyonaka, Osaka, Japan
}

\begin{abstract}
Summary Viral infection is assumed to trigger or exacerbate autoimmune responses against pancreatic beta cells leading to the development of insulin-dependent diabetes mellitus (IDDM). We therefore examined by polymerase chain reaction the presence of two candidate viruses, cytomegalovirus and EpsteinBarr virus, in IDDM pancreases. Pancreas tissues were obtained by biopsy under laparoscopy from 16 recent-onset IDDM patients: age 17-53 years; disease duration 0-7 months; six had flu-like symptoms before onset. Frozen sections were made and subjected to DNA amplification. DNA samples were prepared from the frozen sections and polymerase chain reaction was performed using primers specific to cytomegalovirus, Epstein-Barr virus and control gene for HLA-DP. Cytomegalovirus- and Epstein-Barr virus-infected cells were used for positive control.
\end{abstract}

Southern blot analysis could detect cytomegalovirus DNA from as few as $2 \times 10^{-1}$ cytomegalovirus-infected cells and Epstein-Barr virus DNA from two Epstein-Barr virus-infected cells. This highly sensitive analysis, however, could not detect cytomegalovirus or Epstein-Barr virus genomes in pancreases of recent-onset IDDM. A single copy human gene (HLA-DP) was amplified from all IDDM pancreases indicating that DNA amplification was performed without inhibition. We conclude that cytomegalovirus or Epstein-Barr virus genomes are unlikely to exist in pancreas biopsy specimens of recent-onset IDDM patients. [Diabetologia (1995) 38: 667-671]

Key words Cytomegalovirus, Epstein-Barr virus, polymerase chain reaction, pancreas biopsy, autoimmunity, insulin-dependent diabetes mellitus.
Insulin-dependent diabetes mellitus (IDDM) is caused by selective destruction of pancreatic beta cells. Autoimmune mechanisms and genetic factors are thought to be involved in the pathogenesis. In addition, evidence suggests that the development of diabetes is affected by environmental factors such as viral infection [1]. Coxsackie B4 virus was isolated from the pancreas of a 10-year-old boy who died of diabetic ketoacidosis. Inoculation of the isolated virus in-

Received: 22 August 1994 and in revised form: 22 November 1994

Corresponding author: Dr. N. Itoh, Second Department of Internal Medicine, Osaka University Medical School, 2-2 Yamadaoka, Suita, Osaka 565, Japan

Abbreviations: CMV, Cytomegalovirus; EBV, Epstein-Barr virus; IDDM, insulin-dependent diabetes mellitus; PCR, polymerase chain reaction; ICA, islet cell antibodies. duced hyperglycaemia and insulitis in mice [2]; IDDM occasionally develops after infection of Epstein-Barr virus (EBV) [3-6] or cytomegalovirus (CMV) [7], and congenital infection of CMV or rubella virus can be accompanied by IDDM [8, 9]. CMV genome was detected in lymphocytes of IDDM patients more frequently than in control subjects [10]. Although the relation between virus and IDDM should be clarified by direct examination of the pancreas, there have been very few reports [2, 11] because of the difficult availability of pancreas tissues. We have shown that laparoscopic biopsy was a safe and useful procedure to obtain and analyse pancreas tissues of recent-onset IDDM patients [12,13]. Here we report the results of a search for genomes of two candidate viruses, CMV and EBV, in pancreas biopsy specimens by using polymerase chain reaction (PCR). 


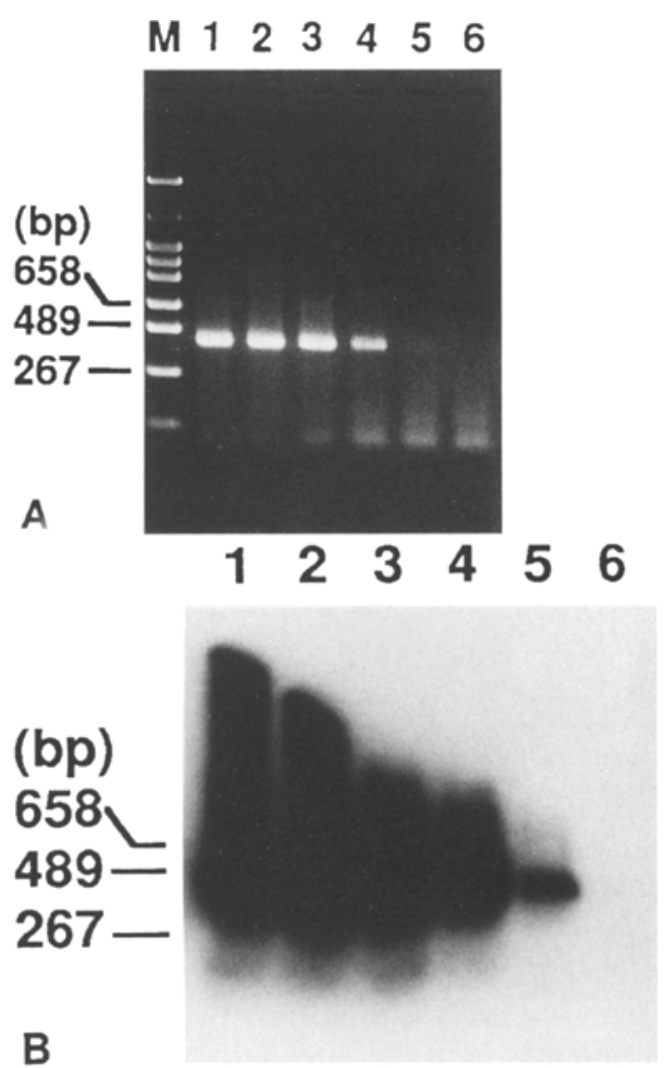

Fig. 1 (A, B). Analysis of PCR products amplified with primers for a 435 base pair sequence of CMV. Ethidium bromide stained gel (A) and autoradiograph (B) (Southern blot analysis) of the gel $\mathbf{A}$. Lane $\mathbf{M}$, molecular weight marker; lane 1 , PCR performed from DNA of $2 \times 10^{2}$ CMV-infected cells; lanes 2-6, PCR performed from DNA of five different $\left(2 \times 10^{2}, 2 \times 10,2,2 \times 10^{-1}, 2 \times 10^{-2}\right) \mathrm{CMV}$-infected cells, respectively, diluted with DNA of uninfected cells to yield the equivalent to $5 \times 10^{3}$ cellular genomes

\section{Subjects, materials and methods}

Subjects. Sixteen newly-diagnosed IDDM patients were subjected to this study. Age of the patients ranged from 17 to 53 years (mean $\pm \mathrm{SD} ; 30.3 \pm 10.5$ ) and the disease duration ranged from 0 to 7 months (mean $\pm S D ; 3.2 \pm 1.9$ ). Nine patients were positive for islet cell antibodies (ICA) assessed by an indirect immunofluorescence method. Six patients had flulike symptoms before onset of IDDM. Complement-fixing antibody for CMV was positive in 9 of 13 patients examined. IgG antibody for EB viral capsid antigen was positive in all ten patients examined, but IgM antibody for that antigen was not found in any patients. After obtaining written informed consent, pancreas biopsy was carried out under laparoscopy. Ethical concerns and the procedure of pancreas biopsy have been described previously $[12,13]$. Consecutive frozen sections $5 \mu \mathrm{m}$-thick were made from pancreas tissues and preserved at $-80^{\circ} \mathrm{C}$ until used. Parts of the sections were analysed by immunohistochemistry as described $[12,13]$. Out of 16 patients, 14 had residual beta cells and seven had insulitis. Seven showed MHC class I hyperexpression in islet and endothelial cells and MHC class II hyperexpression in endothelial cells. There was no significant relation between these histopathological findings, ICA positivity and the presence of circulating anti-CMV or anti-EBV antibodies.
Preparation of samples. DNA was prepared from frozen sections according to the protocol [14] with modification. Five sections were scraped from glass slides with new blades, fixed with phosphate-buffered formalina $(\mathrm{pH} \mathrm{7.0)}$ and dehydrated with ethanol. The samples were then digested with $100 \mu \mathrm{l}$ of buffer containing $100 \mathrm{mmol} / 1$ Tris $/ \mathrm{HCl}(\mathrm{pH} 8.0), 4 \mathrm{mmol} / 1$ EDTA, $400 \mu \mathrm{g} / \mathrm{ml}$ proteinase $\mathrm{K}$ at $55^{\circ} \mathrm{C}$ for $3 \mathrm{~h}$ and boiled for 8 min. A $5-\mu l$ aliquot was used for each DNA amplification. Normal pancreas sections from five subjects who underwent gastrectomy plus partial pancreatectomy for gastric cancer served as a control group. CMV (strain AD169)-infected MRC-5 cell smears and EBV-infected B98.5 cell smears were prepared and subjected to DNA amplification in the same manner as the pancreas tissue for positive control. To evaluate the sensitivity of PCR analysis, we mixed cellular DNA from infected cells with that from control cells with varying ratios. Serial ten-fold dilution of the DNA from infected cells ranging from $2 \times 10^{2}-2 \times 10^{-2}$ cells were mixed with the DNA from uninfected cells to yield the equivalent of $5 \times 10^{3}$ cellular genomes per tube.

DNA amplification. Five pairs of primers were synthesized and used for PCR. One corresponds to a 435 base pair sequence of the major immediate-early antigen gene of CMV (Towne strain) [15]. The sequences are 5'-CCAAGCGGCC TCTGATAACC AAGCC-3' and 5'-CAGCACCATC CTCCTCTTCC TCTGG-3'. One is for a 400 base pair sequence of the late antigen gene of CMV (strain AD169) [15] and its sequences are 5 '-CACCTGTCAC CGCTGCTATA TTTGC-3' and 5'-CACCACGCAG CGGCCCTTGA TGTTT-3'. Two pairs of primers correspond to the long internal repeat fragment of EBV genome [16]. Primers of $5^{\prime}-$ CTTTAAAACT CTAAAAATCA AAACTTTAGA-3' and 5'-ACCAGAAATA GCTGCAGGAC CACTTTATAC-3' yield a 335 base pair product at the first round PCR. Using this product and primers of 5 '-AATGGGCGCC ATTTTGT$3^{\prime}$ and $5^{\prime}$-TCCCTAGAAC TGACAATT-3', a 253 base pair sequence is amplified at the second round PCR (nested PCR). A single copy human gene (HLA-DPB1) was amplified for the internal standard of PCR system. Primers of 5 ' CAGGGATCCG CAGAGAATTA C-3' and $5^{\prime}$ GTCCTGCAGT CACTCACCTC GGCG-3' yield a 294 base pair sequence of the HLA-DPB1 gene [17]. Forty cycles of PCR were carried out in a thermal cycler (Perkin-Elmer/Cetus, Norwalk, Conn., USA) at a reaction volume of $50 \mu \mathrm{l}$ containing $50 \mathrm{mmol} / \mathrm{l} \quad \mathrm{KCl}, 10 \mathrm{mmol} / 1$ Tris $/ \mathrm{HCl}$ (pH 8.3), $1.5 \mathrm{mmol} / 1 \mathrm{MgCl}_{2}, 200 \mu \mathrm{mol} / \mathrm{l}$ each $\mathrm{dNTP}, 0.001 \%$ gelatin, $0.2 \mu \mathrm{mol} / 1$ each primers, 1.25 units of Taq DNA Polymerase (ampli Taq, Perkin-Elmer/Cetus) and template DNA. Thermal cycling consisted of denaturation at $94^{\circ} \mathrm{C}$, annealing at $60^{\circ} \mathrm{C}$ and polymerization at $72^{\circ} \mathrm{C}$ for $1 \mathrm{~min}$ each.

Detection of amplified products. Amplified products were run on $2 \%$ agarose gel followed by ethidium bromide staining. Southern blot analysis was also performed for detection of viral genomes with ${ }^{32} \mathrm{P}$-labelled oligonucleotide probe complementary to a central region of the amplified DNA $[15,16]$. The sequences are 5'-GAGGCTATTG TAGCCTACAC TTTGG-3' for the major immediate-early antigen gene of CMV, 5'-GTCGCCTGCA CTGCCAGGTG CTTCG-3' for the late antigen gene of CMV and 5'-TATCTTTAGA GGGGAAAAGA GGAATAAG-3' for the long internal repeat fragment of EBV. Amplified products were transferred onto nylon membranes and hybridized with ${ }^{32} \mathrm{P}$-end-labelled oligonucleotide probes. Autoradiography was performed at $-80^{\circ} \mathrm{C}$ for $4 \mathrm{~h}$ and $24 \mathrm{~h}$. 

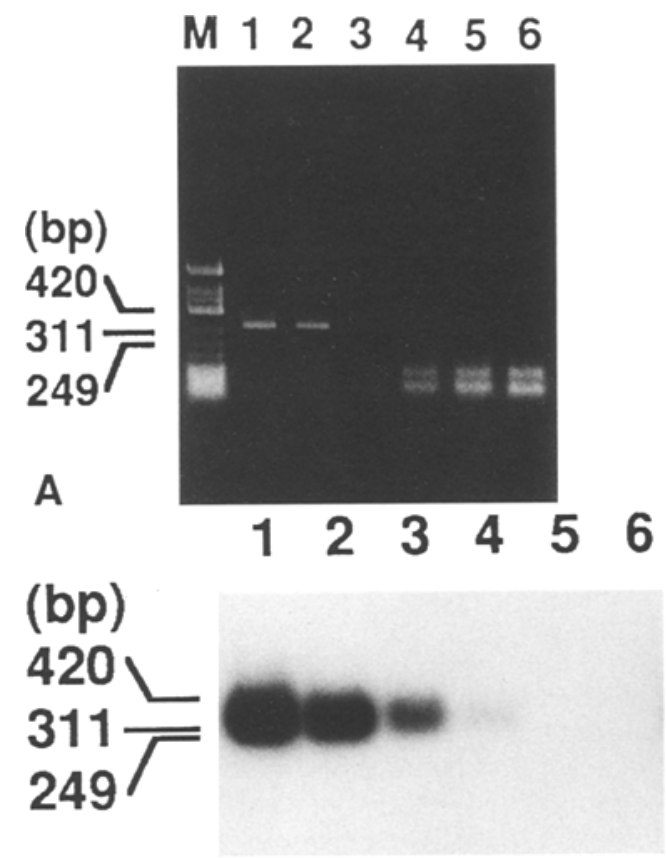

B

Fig. 2 (A, B). Analysis of PCR products amplified with primers for a 335 base pair sequence of EBV. Ethidium bromide stained gel (A) and autoradiograph (B) (Southern blot analysis) of the gel $\mathbf{A}$. Lane M, molecular weight marker; lane 1, PCR performed from DNA of $2 \times 10^{2}$ EBV-infected cells; lanes 2-6, PCR performed from DNA of five different $\left(2 \times 10^{2}, 2 \times 10,2,2 \times 10^{-1}, 2 \times 10^{-2}\right)$ EBV-infected cells, respectively, diluted with DNA of uninfected cells to yield the equivalent to $5 \times 10^{3}$ cellular genomes

\section{Results}

Sensitivity of PCR. The sensitivity of PCR was determined by a dilution study mixing DNA from virus-infected cells with that from uninfected cells. Two pairs of primers for CMV could detect DNA from as few as two infected cells diluted with DNA from a total of $5 \times 10^{3}$ uninfected cells on ethidium bromide stained gels (Fig.1A). Southern blot analysis of CMV gave tentimes higher sensitivity than ethidium bromide staining (Fig. 1B). The first round PCR for EBV detected DNA from as few as 20 infected cells in DNA from a total of $5 \times 10^{3}$ uninfected cells on ethidium bromide stained gels (Fig. 2A). Southern blot analysis of EBV also gave tentimes higher sensitivity than ethidium bromide staining (Fig. 2B). Nested PCR did not change the sensitivity and gave the same results as the first round PCR.

$P C R$ from frozen pancreas sections. HLA-DPB1 gene could be amplified from all frozen pancreas sections (Fig. 3A). CMV genome was examined in pancreas sections using two pairs of primers, but no band was detected on ethidium bromide stained gels or Southern blot analysis (Fig. 3B). EBV genome was not amplified from any pancreas sections (Fig. 3C).

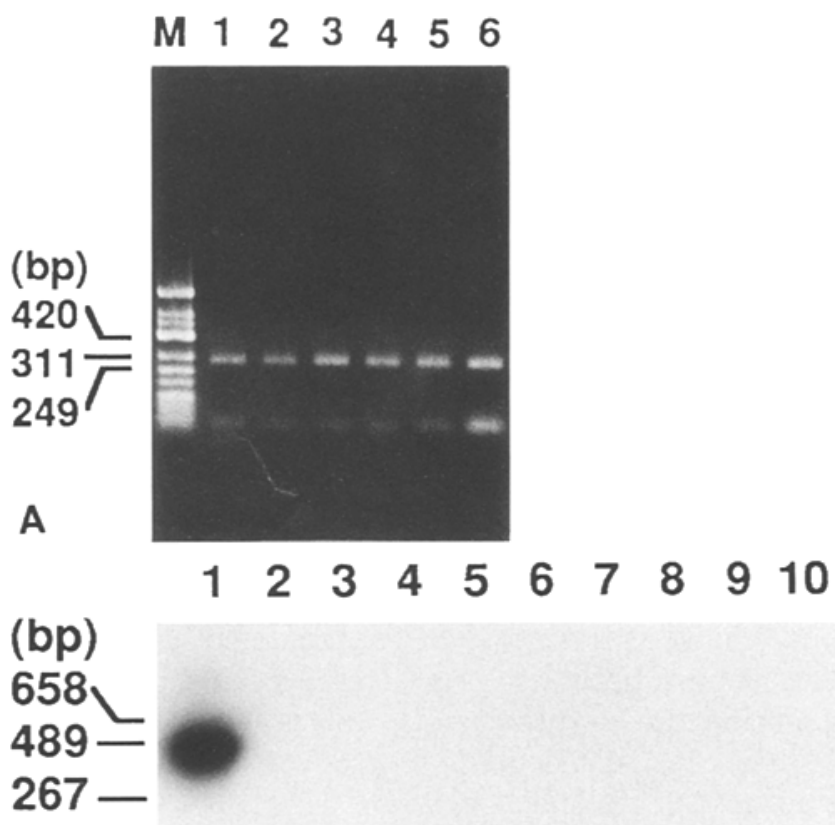

B

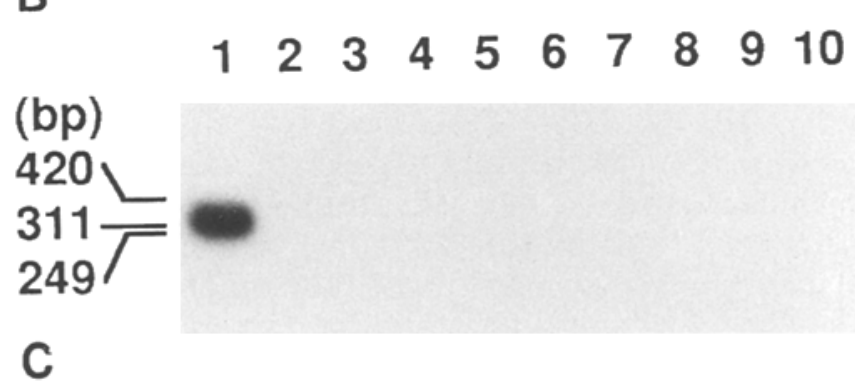

Fig. 3 (A-C). Ethidium bromide stained gel analysis of PCR products amplified with primers for a 294 base pair sequence of HLA-DPB1 gene (A): Lane M, molecular weight marker; lanes 1-5, PCR performed from DNA of the pancreas of five different patients with IDDM; lane 6, PCR from DNA of a control pancreas. Southern blot analysis of PCR products amplified with primers for a 435 base pair sequence of CMV (B) and for a 335 base pair sequence (C): Lane 1, PCR performed from DNA of infected cells (positive control); lanes 2-9, PCR from DNA of the pancreas of eight different patients with IDDM; lane 10, from DNA of a control pancreas

\section{Discussion}

IDDM occasionally develops after viral infection [29]. The mechanism which destroys pancreatic beta cells is not yet clear. Virus might infect the beta cells and destroy them by cytopathic effect leading either to the initiation of autoimmune responses or directly to diabetes. Otherwise, the virus might remain in beta cells to trigger autoimmune mechanisms by molecular mimicry $[10,18,19]$. Persistent viral infection is possibly related to a latent period before onset of IDDM [1] and/or to a finding that 10 of 16 patients in our study developed diabetes without symptoms of acute viral infection. We examined the existence of genomes of two viruses, CMV 
and EBV. They are double stranded DNA viruses belonging to the herpesvirus group and well known to infect target cells persistently. Several clinical reports indicated that these viruses might play roles in the pathogenesis of IDDM [3-8]. In addition, an experimental study showed that CMV infection produced antibodies which reacted with pancreatic islet cell specific antigen [20]. EBV genome was disclosed in salivary glands of patients with Sjögren's syndrome, another T-cell-mediated autoimmune disease [21].

We employed PCR to detect viral genomes in pancreas tissues of recent-onset IDDM patients. Our sensitive PCR method is considered to be sufficient to detect CMV and EBV DNAs in the tissue. Since the sensitivity of PCR depends on various factors, we preliminarily tested several amplification conditions and synthesized primers which had been reported to be effective for the detection of viral genomes in clinical specimens $[15,16,21-24]$. We subsequently chose the most sensitive combination of an amplification condition and primers, and employed it as our procedure. As a result we could detect CMV DNA from as few as $2 \times 10^{-1} \mathrm{CMV}$-infected cells and EBV DNA from two EBV-infected cells. Although the exact number of viral copies in an infected cell is unclear, other studies using the same PCR system as ours would give comparable data regarding the sensitivity. Demmler et al. [15] detected CMV in a $10^{-4}$ dilution of a tissue culture suspension that had an infectivity titre of $10^{5.3}$ TCID $_{50} / 0.1 \mathrm{ml}$. Shibata et al. [22] detected one CMV plaque-forming unit by their PCR. Ross et al. [24] showed that EBV DNA from 10 infected cells in a total of $2 \times 10^{6}$ cells was detectable. PCR is thus a sensitive and useful procedure for the detection of CMV- or EBV-infected cells. Another advantage of PCR is the availability of various tissues as DNA templates. From frozen tissues preserved at $-80^{\circ} \mathrm{C}$, we could clearly amplify a single copy human gene (HLA-DPB1) in all IDDM patients. This means that frozen pancreas sections should give us useful and sufficient information as DNA templates for PCR.

Despite using highly sensitive PCR, we could not detect CMV or EBV genomes in pancreas tissues of recent-onset IDDM patients. This is not due to the paucity of pancreas islet cells that viruses might infect. Morphological analysis revealed that beta cells remained in $0.24 \pm 0.24$ (mean $\pm \mathrm{SD}$ ) \% in volume of used pancreases [25]. This means that the sensitivity of our PCR that can detect two EBV-infected cells $(0.04 \%)$ or $0.2 \mathrm{CMV}$-infected cells $(0.004 \%)$ in a total of $5 \times 10^{3}$ cells is sufficient to detect these viral genomes, if any, in remaining beta cells. In our study, there were six patients who showed flu-like symptoms before onset of diabetes. Although we have to think about the possibility that viruses transiently in- fected the beta cells and were involved in the occurrence of diabetes, we conclude that CMV or EBV genomes were not proven to be present in the pancreas after the onset of IDDM.

Acknowledgements. We wish to thank Drs. I. Mineo and K. Hotta for technical assistance. We also thank Mr. T. Tanaka for preparing oligonucleotides and Drs. Y. Mikami and M. Kyo for their kind help. This work was supported in part by the Scientific Research Fund from the Ministry of Education, Science and Culture of Japan, a grant for diabetes research from Otsuka Pharmaceutical Co., Ltd. and a grant from the Mochida Memorial Foundation for Medical and Pharmaceutical Research.

\section{References}

1. Eisenbarth GS (1986) Type I diabetes mellitus. A chronic autoimmune disease. $\mathrm{N}$ Engl J Med 314: 1360-1368

2. Yoon J-Y, Austin M, Onodera T, Notkins AL (1979) Virusinduced diabetes mellitus. Isolation of a virus from the pancreas of a child with diabetic ketoacidosis. N Engl J Med 300: 1173-1179

3. Burgess JA, Kirkpatrick KL, Menser MA (1974) Fulminant onset of diabetes mellitus during an attack of infectious mononucleosis. Med J Aust 2: 706-707

4. Ganda OP, Soeldner JS, Gleason RE, Smith TM, Kilo C, Williamson JR (1977) Monozygotic triplets with discordance for diabetes mellitus and diabetic microangiopathy. Diabetes 26: 469-479

5. Namba M, Kuwajima M, Fukumoto Y et al. (1978) A case of acute onset, insulin dependent diabetes following an attack of infectious mononucleosis. J Jpn Diab Soc 21: 10731082

6. Minakami H, Nakayama H, Aoki S et al. (1982) Diabetes mellitus during the course of infectious mononucleosis. $J$ Jpn Diab Soc 25: 625-631

7. Nakano S, Matsuda T, Endo M, Ogami Y, Otsuki M (1993) A case of insulin-dependent diabetes associated with painless acute pancreatitis. J Jpn Diab Soc 36: 807-812

8. Ward KP, Galloway WH, Auchterlonie IA (1979) Congenital cytomegalovirus infection and diabetes. Lancet I: 497 (Letter)

9. Patterson K, Chandra RS, Jenson AB (1981) Congenital rubella, insulitis, and diabetes mellitus in an infant. Lancet I: 1048-1049 (Letter)

10. Pak CY, Eun H-M, McArthur RG, Yoon J-Y (1988) Association of cytomegalovirus infection with autoimmune type I diabetes. Lancet II: $1-4$

11. Foulis AK, Farquharson MA, Cameron SO, McGill M, Schönke H, Kandolf R (1990) A search for the presence of the enteroviral capsid protein VP1 in pancreases of patients with type 1 (insulin-dependent) diabetes and pancreases and hearts of infants who died of coxsackieviral myocarditis. Diabetologia 33: 290-298

12. Hanafusa T, Miyazaki A, Miyagawa J et al. (1990) Examination of islets in the pancreas biopsy specimens from newlydiagnosed type 1 (insulin-dependent) diabetic patients. Diabetologia 33: 105-111

13. Itoh N, Hanafusa T, Miyazaki A et al. (1993) Mononuclear cell infiltration and its relation to the expression of major histocompatibility complex antigens and adhesion molecules in pancreas biopsy specimens from newly diagnosed insulin-dependent diabetes mellitus patients. J Clin Invest 92: 2313-2322 
14. Innis MA, Gelfand DH, Sninsky JJ, White TJ (1990) PCR protocols. A guide to methods and applications. 1st edn. Academic Press Inc., San Diego

15. Demmler GJ, Buffone GJ, Schimbor CM, May RA (1988) Detection of cytomegalovirus in urine from newborns by using polymerase chain reaction DNA amplification. J Infect Dis $158: 1177-1184$

16. Herbst H, Niedobitek G, Kneda M et al. (1990) High incidence of Epstein-Barr virus genomes in Hodgkin's disease. Am J Pathol 137: 13-18

17. Yamagata K, Hanafusa T, Nakajima H et al. (1991) HLADP and susceptibility to insulin-dependent diabetes mellitus in Japanese. Tissue Antigens 38: 107-110

18. Oldstone MBA (1987) Molecular mimicry and autoimmune disease. Cell 50: 819-820

19. Krolewski AS, Warram JH, Rand LI, Kahn CR (1987) Epidemiologic approach to the etiology of type I diabetes mellitus and its complication. N Engl J Med 317: 1390-1398

20. Pak CY, Cha CY, Rajotte RV, McArthur RG, Yoon J-W (1990) Human pancreatic islet cell specific 38 kilodalton autoantigen identified by cytomegalovirus-induced monoclonal islet cell autoantibody. Diabetologia 33: 569-572
21. Saito I, Servenius B, Comptom T, Fox RI (1989) Detection of Epstein-Barr virus DNA by polymerase chain reaction in blood and tissue biopsies from patients with Sjögren's syndrome. J Exp Med 169: 2191-2198

22. Shibata D, Martin WJ, Appleman MA, Causey DM, Leedom JM, Arnheim N (1988) Detection of cytomegalovirus DNA in peripheral blood of patients infected with human immunodeficiency virus. J Infect Dis 158: 1185-1192

23. Löhr JM, Oldstone MBA (1990) Detection of cytomegalovirus nucleic acid sequences in pancreas in type 2 diabetes. Lancet 336: 644-648

24. Ross CW, Schlegelmilch JA, Grogan TM, Weiss LM, Shnitzer B, Hanson CA (1992) Detection of Epstein-Barr virus genome in $\mathrm{Ki}-1$ (CD30)-positive, large-cell anaplastic lymphomas using the polymerase chain reaction. Am J Pathol 141: 457-465

25. Itoh N, Hanafusa T, Miyagawa J et al. (1992) Transthyretin (prealbumin) in the pancreas and sera of newly diagnosed type 1 (insulin-dependent) diabetic patients. J Clin Endocrinol Metab 74: 1372-1377 